\title{
Podocytes Express IL-6 and Lipocalin 2/ Neutrophil Gelatinase-Associated Lipocalin in Lipopolysaccharide-Induced Acute Glomerular Injury
}

\author{
Sarah J. Lee ${ }^{a, b}$ Emily Borsting ${ }^{a} \quad$ Anne-Emilie Declèves ${ }^{b}$ Prabhleen Singh ${ }^{a, b}$ \\ Robyn Cunard ${ }^{a, b}$

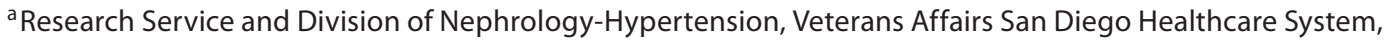 \\ Veterans Medical Research Foundation, San Diego, and ${ }^{\mathrm{b}}$ Department of Medicine, University of California San Diego, \\ La Jolla, Calif., USA
}

\section{Key Words}

Acute kidney injury · Albuminuria $\cdot$ Glomeruli •

Interleukin-6 $\cdot$ Lipocalin $\cdot$ Lipopolysaccharides

\begin{abstract}
Background/Aims: Acute kidney injury (AKI) contributes to significant morbidity and mortality in the intensive care unit (ICU). Plasma levels of interleukin (IL)-6 predict the development of AKI and are associated with higher mortality in ICU patients with AKI. Most studies in AKI have focused on the tubulo-interstitium, despite evidence of glomerular involvement. In the following study, our goals were to investigate the expression of IL- 6 and its downstream mediators in septic-induced AKI. Methods: Podocytes were treated in vitro with lipopolysaccharide (LPS) and mice were treated with LPS, and we evaluated IL- 6 expression by real-time PCR, ELISA and in situ RNA hybridization. Results: Following LPS stimulation, IL- 6 is rapidly and highly induced in cultured podocytes and in vivo in glomeruli and infiltrating leukocytes. Surprisingly, in direct response to exogenous IL-6, podocytes produce lipocalin-2/neutrophil gelatinase-associated lipocalin (Lcn2/Ngal). LPS also potently induces Lcn2/ Ngal expression in podocytes in culture and in glomeruli in vivo. Intense Lcn2/Ngal expression is also observed in IL-6
\end{abstract}

knockout mice, suggesting that while IL-6 may be sufficient to induce glomerular Lcn2/Ngal expression, it is not essential. Conclusions: The glomerulus is involved in septic AKI, and we demonstrate that podocytes secrete key mediators of AKI including IL- 6 and Lcn2/Ngal.

Copyright $\odot 2012$ S. Karger AG, Basel

\section{Introduction}

Acute kidney injury (AKI) contributes to significant morbidity and mortality in the intensive care unit (ICU) [1]. One of the most common causes of AKI is sepsis, and its pathophysiology is related to alterations in renal hemodynamics, inflammation, endothelial dysfunction, tubular obstruction and glomerular thrombosis $[2,3]$. Most studies investigating AKI have focused on pathophysiologic changes in the tubulo-interstitium, despite early work suggesting that $\mathrm{AKI}$ is associated with changes in the glomeruli $[4,5]$. Sepsis-mediated AKI causes albuminuria due to transient podocyte dysfunction, foot process effacement and decreased tubular reabsorption

\section{S.L. and E.B. contributed equally to this paper.}

\section{KARGER}

Fax +4161306 1234 E-Mail karger@karger.ch www.karger.com
(C) 2012 S. Karger AG, Basel $1660-2129 / 12 / 1214-0086 \$ 38.00 / 0$

Accessible online at: www.karger.com/nee
Robyn Cunard, MD

Research and Medicine Services, Division of Nephrology

Veterans Affairs San Diego Healthcare System, Mail Code 151

3350 La Jolla Village Drive, San Diego, CA 92161 (USA)

E-Mail rcunard@ucsd.edu 
of filtered proteins [6-8]. Indeed, treatment with plasma from burn patients with sepsis-associated AKI reduces podocyte viability, downregulates nephrin expression and causes redistribution of actin fibers and nestin filaments $[9,10]$. These studies suggest that podocyte dysfunction is an important contributor to septic AKI.

Sepsis-mediated AKI is associated with dramatic rises in the expression of chemokines and cy tokines, including interleukin (IL)-6, tumor necrosis factor (TNF)- $\alpha$, IL-1 $\beta$, IL-18, IL-8, fractalkine, IL-33 and IL-10, but the functional relevance of cytokine expression is incompletely understood [for a review, see ref. 11]. Studies suggest that various infiltrating leukocyte subsets, including neutrophils [12], macrophages [13] and resident tubular cells [14], are the major sources of inflammatory cytokines. However, we and others have shown that podocytes secrete cytokines and chemokines, including IL-1 [15], IL-6 $[16,17]$, TNF- $\alpha$, transforming growth factor- $\beta$, IL-8 [18] and monocyte chemoattractant protein (MCP)-1 [19-22] in various conditions. In this study, we explored the hypothesis that podocytes may also secrete inflammatory mediators in sepsis, and play a pathogenic role in septic AKI.

It has been shown that IL- 6 may play an important role in the pathophysiology of septic AKI [2, 11], as IL-6 levels predict the development of AKI and are associated with higher mortality in ICU patients with AKI [23, 24]. However, some studies suggest that IL-6 may function in an anti-inflammatory manner [for a review, see ref. 25] and be a marker rather than a mediator of inflammation [26]. In mice, lipopolysaccharide (LPS) causes sepsis-induced AKI. In these studies, we use a low-dose LPS model to induce transient podocyte dysfunction [6], and we show that LPS induces podocyte secretion of IL-6. In these studies, we also observe that podocytes express and signal via the IL-6 receptor.

In ischemic kidneys, lipocalin-2/neutrophil gelatinase-associated lipocalin (Lcn2/Ngal) is typically expressed by the thick ascending loop of Henle, macula densa and intercalated cells of the collecting duct [27]. Lcn $2 / \mathrm{Ngal}$ has been proposed as a promising new biomarker to identify tubular injury-associated AKI $[28,29]$ and may distinguish septic from non-septic AKI [30]. A novel observation in our studies is that in direct response to exogenous IL-6, podocytes produce Lcn2/Ngal. LPS also potently induces Lcn2/Ngal expression in podocytes. Interestingly, we observe intense glomerular and tubular expression of Lcn2/Ngal expression in IL-6 knockout (KO) mice, suggesting that while IL- 6 may be sufficient to induce glomerular Lcn2/Ngal expression, it is not essential. Finally, we detect higher albuminuria and MCP-1 expression in LPS-treated IL-6 KO mice compared with controls, suggesting that absence of IL- 6 may impair podocyte function in LPS-induced AKI. These studies suggest that manipulation of podocyte function may provide a new therapeutic strategy for the management of sepsis-induced AKI.

\section{Materials and Methods}

C57BL/6 mice and IL- $6 \mathrm{KO}$ mice on a C57BL/6 background

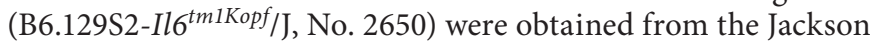
Laboratories (Bar Harbor, Maine, USA). Lcn2/Ngal KO mice (C57BL/6 background) were a kind gift from Dr. Tak Mak (University of Toronto, Toronto, Ont., Canada) [31]. Mice were housed and handled in accordance with VA and NIH guidelines under protocols approved by the Institutional Animal Care and Use Committee. We treated 9- to 12-week-old C57BL/6 mice with LPS (10 $\mu \mathrm{g} / \mathrm{g}$ body weight i.p.; Sigma-Aldrich, St. Louis, Mo., USA; 4524, Escherichia coli 055:B5): $\mathrm{n}=12 \mathrm{C} 57 \mathrm{BL} / 6, \mathrm{n}=6 \mathrm{IL}-6 \mathrm{KO}$ and $\mathrm{n}=7 \mathrm{Lcn} 2 / \mathrm{Ngal}$ KO mice or phosphate-buffered saline (PBS) control ( $\mathrm{n}=7 \mathrm{C} 57 \mathrm{BL} / 6$ mice, $\mathrm{n}=4 \mathrm{IL}-6 \mathrm{KO}$ and $\mathrm{n}=4 \mathrm{Lcn} 2 / \mathrm{Ngal} \mathrm{KO}$ mice). Mice were acclimatized for $24 \mathrm{~h}$ prior to LPS treatment and housed in metabolic cages. Mice were euthanized 3, 12, 24 and $48 \mathrm{~h}$ after LPS injection.

\section{Podocytes}

Conditionally immortalized podocytes were kindly provided by Drs. Peter Mundel and Stuart Shankland, and propagated at $33^{\circ} \mathrm{C}$ (permissive conditions) on type I collagen-coated plastic plates with IFN- $\gamma$ as previously described [32]. For differentiation, cells were transferred to $37^{\circ} \mathrm{C}$ for 14 days and semi-quantitative PCR studies were used to verify expression of synaptopodin and WT-1.

To propagate primary podocytes, kidneys from 6 - to- 8-weekold C57BL/6 mice were perfused with Dynabeads (Epoxy M-450; Life Technologies, Grand Island, N.Y., USA), decapsulated and digested at $37^{\circ} \mathrm{C}$ in a collagenase solution $(1 \mathrm{mg} / \mathrm{ml}$; Sigma-Aldrich) [33]. Minced kidneys were strained and a magnet particle concentrator was used until the purity of the glomeruli reached $>95 \%$. The glomeruli were then transferred to collagen-coated dishes with growth media [22] and incubated at $37^{\circ} \mathrm{C}$ for $5-7$ days. Adherent cells were harvested from plates and strained $(40 \mu \mathrm{m})$, and the magnet catcher removed any remaining Dynabeads. Cells were transferred to collagen-coated dishes and incubated at $37^{\circ} \mathrm{C}$. Passage 2-3 cells were used. To validate that the cells were podocytes, they were grown on coverslips and stained with anti-synaptopodin antibody (clone G1D4; Fitzgerald Industries, Acton, Mass., USA) and WT-1 (SC-192; Santa Cruz Biotech, Santa Cruz, Calif., USA).

\section{Cytokine and Albumin ELISA}

Fully differentiated podocytes (14 days) were replated into a 24-well plate. The next day, the podocytes were treated with LPS (10 ng/ml) or control in 1\% fetal bovine serum in RPMI 1640 (Life Technologies) without antibiotics. At various time points, culture supernatant concentrations of IL- 6 were determined by sandwich 
ELISA with the OPTEIA ${ }^{\mathrm{TM}}$ set (BD Pharmingen, San Diego, Calif., USA). Urinary albumins and creatinines were assessed by ELISA using the Albuwell $\mathrm{M}$ and Creatinine Companion kits (Exocell, Philadelphia, Pa., USA).

\section{Real-Time PCR and Microarray Studies}

Fully differentiated conditionally immortalized podocytes were treated with $10 \mathrm{ng} / \mathrm{ml}$ IL-6 (R\&D Systems, Minneapolis, Minn., USA) and RNA was prepared with TRIzol (Life Technologies) and cleaned up with the RNeasy Plus Kit (Qiagen, Valencia, Calif., USA). RNA from control and IL-6-treated podocytes was analyzed by microarray assay (GeneChip ${ }^{\circledR}$ Murine Genome, U74/ Av2 Array; Affymetrix, Santa Clara, Calif., USA) with the assistance of the Veterans Medical Research Foundation GeneChip ${ }^{\mathrm{TM}}$ microarray core.

cDNA was prepared with the Superscript $\mathrm{II}^{\circledR}$ kit (Life Technologies) and real-time PCR studies were performed as previously described [22]. For RNA quantification, TaqMan ${ }^{\circledR}$ gene expression assays (mIL-6 Mm00446190_m1, MCP-1 Mm00441242, IL6ro Mm00439653_m1) with TaqMan Universal PCR Master Mix or Power SYBR ${ }^{\circledR}$ Green PCR Mastermix (Applied Biosystems) were performed. Primers for Lcn2/Ngal are 5'-GGACCAGGGCTGTCGCTACT- ${ }^{\prime}$ ' and 5'-GGTGGCCACTTGCACATTGT-3' and nephrin 5'-ACCCTCCAGTTAACTTGTCTTTGG-3', 5'-ATGCAGCGGAGCCTTTGA-3'. Amplification efficiencies were normalized against RPL19 and relative fold increases were calculated using the Pfaffl technique of relative quantification $[22,34]$.

\section{Western Blotting}

Cell lysates were prepared with cell lysis buffer (Cell Signaling, Beverly, Mass., USA) with protease inhibitors [35]. Samples were run on NuPAGE bis-Tris gels (Life Technologies) and transferred onto nitrocellulose membranes (Life Technologies). The following antibodies were used: anti-IL-6r $\alpha$ (AF1830; R\&D Systems), gp130 (sc-656) and actin (sc-1616; Santa Cruz Biotech). Detection was performed with ECL Plus detection reagents (GE Healthcare, Piscataway, N.J., USA).

\section{In situ RNA Hybridization}

Kidneys were perfused with PBS, fixed in $4 \%$ paraformaldehyde (PFA), cryopreserved in 30\% sucrose-DEPC-PBS, embedded in optimal cutting temperature (Tissue-Tek; Sakura Finetek, Torrance, Calif., USA), and snap frozen in a dry ice/2-methylbutane slurry. Vascular endothelial growth factor (VEGF) expression vector (pBluescript-VEGF) was a kind gift from Dr. Susan Quaggin's laboratory (University of Toronto). Additionally, we cloned murine Lcn2/Ngal and IL-6 expression vectors into pSPT19 (pSPT19-Lcn2 and pSPT19-IL-6) using the following primers for Lcn2/Ngal: 5'-GACCTAGAAGCTTTGGAAACC-3', 5'-GCCACACTCGGTACCCATTCAG-3', and IL-6 5'-CCCAAGCTTATGAAGTTCCTCTCTGCAAGA-3', 5'-CCGGAATTCCTAGGTTTGCCGAGTAGATCT-3'. Lcn2/Ngal-, VEGF- and IL-6-digoxigenin (DIG)-labeled riboprobes were generated (DIG RNA labeling kit; Roche Diagnostics, Indianapolis, Ind., USA). Sections were dried $\mathrm{o} / \mathrm{n}$ and permeabilized with RNase-free proteinase $\mathrm{K}(20 \mu \mathrm{g} / \mathrm{ml})$ for $5 \mathrm{~min}$ at $37^{\circ} \mathrm{C}$ and washed in PBS-DEPC. Next sections were re-fixed in $4 \%$ PFA, washed in PBS-DEPC and prehybridized in $5 \times$ SSC with $50 \%$ deionized formamide, yeast tRNA and heparin. The DIG-labeled riboprobes $(1,000 \mathrm{ng} / \mathrm{ml})$ were hybridized $\mathrm{o} / \mathrm{n}$ at $60^{\circ} \mathrm{C}$ and then washed with $50 \%$ formamide $/ 0.2 \times \mathrm{SSC}$ at $50^{\circ} \mathrm{C}$. Detection with sheep anti-DIG-alkaline phosphatase (1:500) and then nitroblue tetrazolium solution and 5-bromo-4-chloro-3-indolyl-phosphate solution was performed, and slides were counterstained with $0.1 \%$ nuclear fast red, washed and mounted [36].

\section{Statistics}

Differences were analyzed using Student's t test and ANOVA with post hoc Tukey tests for pairwise comparisons. Analysis was accomplished with SPSS 20 (IBM, Armonk, N.Y., USA).

\section{Results}

\section{LPS Induces IL-6 Expression in Podocytes}

LPS is a classic inducer of inflammation and it stimulates a myriad of cytokines, including IL-6 [37]. Fully differentiated immortalized podocytes were exposed to 10 $\mathrm{ng} / \mathrm{ml}$ of LPS, and we analyzed IL-6 mRNA and protein expression at various time points. Quantitative PCR revealed a rapid burst of IL- 6 mRNA synthesis by $2 \mathrm{~h}$ with an equally profound downregulation by $4 \mathrm{~h}$ (fig. 1a). ELISA analysis on the supernatants from LPS-treated cell supernatants detected IL- 6 protein expression by $2 \mathrm{~h}$ (fig. 1b). Consistent with mRNA kinetics, near-maximal IL- 6 protein levels were noted by $4 \mathrm{~h}$. These data suggest exquisite control of IL- 6 production likely at the level of transcription. Interestingly, higher doses of LPS did not further increase IL- 6 .

\section{Podocytes Express the IL-6 Receptor}

The IL- 6 receptor is composed of two subunits, the $\alpha$ chain (IL-6r $\alpha$, glycoprotein (gp) 80 [38]) and the $\beta$ chain (the signal transducer gp130, [39]). IL-6 mediates its biological effects through either 'classical signaling' or 'trans-signaling' [for a review see ref. 40]. The classical pathway involves a membrane-bound IL-6 receptor (mIL6r $\alpha$ ) [41], whereas trans-signaling occurs through a soluble IL-6 receptor (sIL6r $\alpha$ ) [42]. To determine if podocytes express IL-6r $\alpha$, we performed Western blotting and discovered that podocytes express both IL6r $\alpha$ and gp130 protein (fig. 1c) as well as mRNA [unpubl. observations]. We did not detect substantial amounts of sIL6r $\alpha$ in the supernatant suggesting that fully differentiated podocytes in culture probably do not secrete IL- 6 and facilitate trans-signaling (fig. 1c).

\section{LPS Induces Glomerular Expression of IL-6}

Administration of LPS (10 $\mu \mathrm{g} / \mathrm{g}$, i.p.) to C57BL/6 mice induces transient podocyte dysfunction, whereas higher doses $(15 \mu \mathrm{g} / \mathrm{g})$ cause sepsis-induced AKI. Thus, we in- 


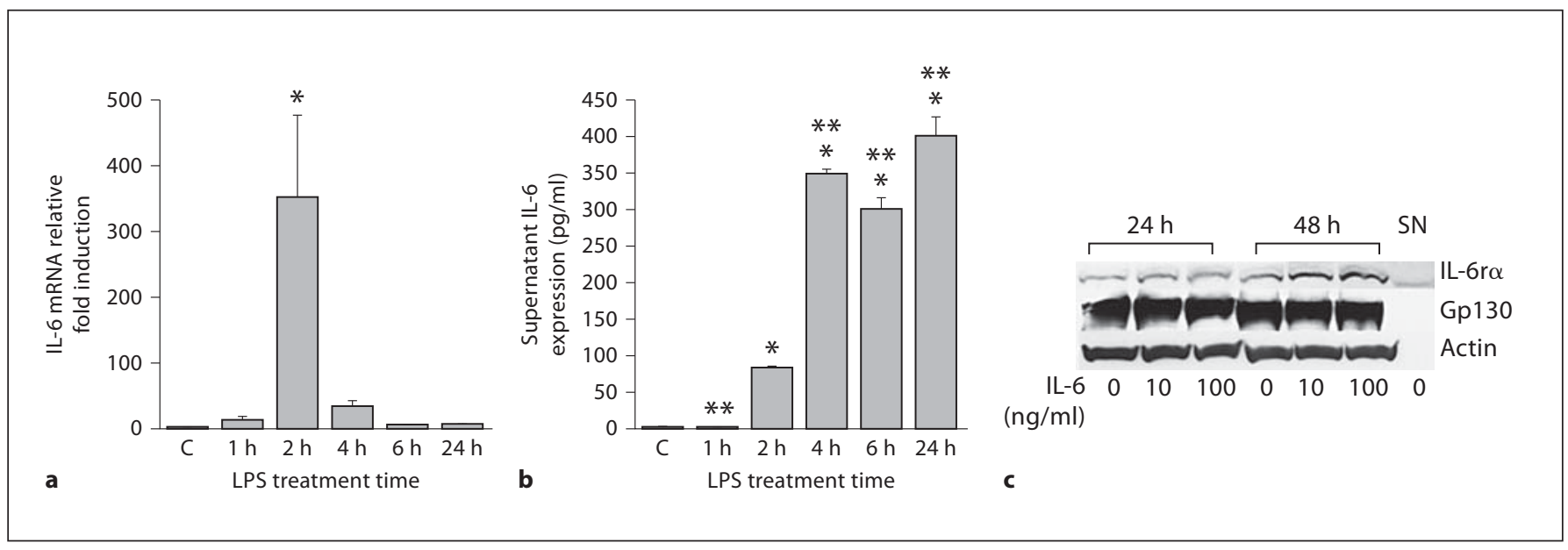

Fig. 1. LPS augments podocyte IL-6 expression and podocytes express the IL- 6 receptor. Fully differentiated transformed podocytes were treated with $10 \mathrm{ng} / \mathrm{ml}$ LPS. a IL-6 mRNA was evaluated by real-time PCR at various time points. Results are the average of studies performed at least three times, ${ }^{*} \mathrm{p}<0.05 \mathrm{vs}$. control (C) podocytes and bars represent SEM. b Culture supernatant
IL- 6 was evaluated by ELISA. Results are representative of studies performed at least three times. ${ }^{*} \mathrm{p}<0.05$ vs. control, ${ }^{* *} \mathrm{p}<0.05$ vs. 2-hour LPS treatment. c. Fully differentiated podocytes were treated with IL-6, and at 24 and $48 \mathrm{~h}$ Western blotting for IL-6r $\alpha$, gp130 and actin was performed on cell lysates. SN = Podocyte culture supernatant at $48 \mathrm{~h}$.
Fig. 2. In vivo LPS induces glomerular expression of IL-6 mRNA. C57BL/6 mice were treated with PBS (a) or LPS $(10 \mu \mathrm{g} / \mathrm{g})$ and kidneys were harvested at 3 (b, c, e, f) and $12 \mathrm{~h}(\mathbf{d})$. In situ hybridization of IL-6 mRNA demonstrates glomerular staining 3 and $12 \mathrm{~h}$ after LPS treatment $(\mathbf{b}, \mathbf{d})$. AS $=$ Anti-sense. IL- 6 was also expressed by infiltrating leukocytes (arrow, e) and in the thin loops of Henle (f).

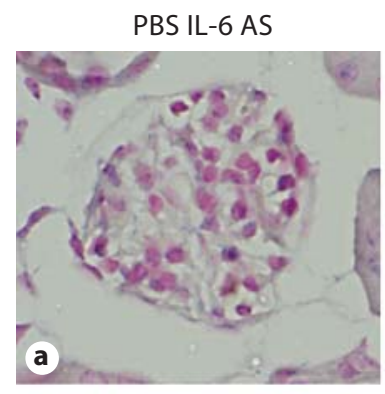

LPS 12-hour IL-6 AS

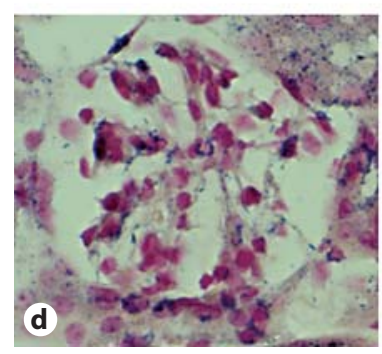

LPS 3-hour IL-6 AS

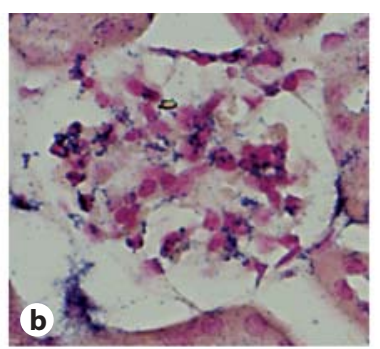

LPS 3-hour IL-6 AS

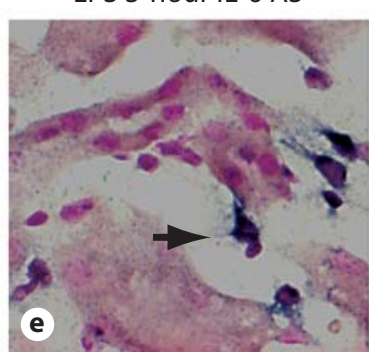

LPS 3-hour IL-6 sense

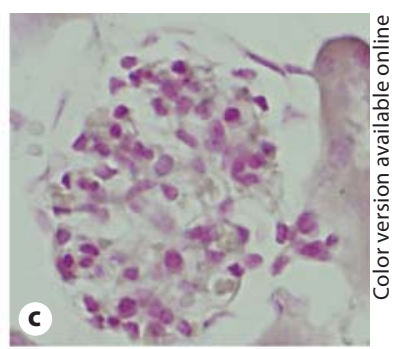

LPS 3-hour IL-6 AS

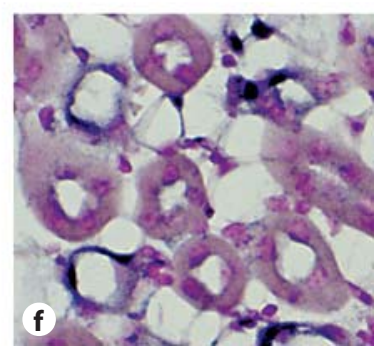

jected C57BL/6 mice with LPS (10 $\mu$ g/g i.p.) or PBS, and evaluated whether in vivo podocytes treated with LPS express IL-6. IL-6 is secreted; therefore, precise cellular identification requires mRNA localization. In our in situ studies, as early as $3 \mathrm{~h}$ (fig. $2 \mathrm{~b}$ ) and up to $12 \mathrm{~h}$ after LPS injection, we observed glomerular staining of IL- 6 mRNA (fig. 2d). There was evidence of IL-6 mRNA-expressing cells in the interstitium, likely corresponding to infiltrating monocytes/macrophages (fig. 2e) [13]. We did not observe proximal tubular staining of IL- 6 at any of the time points investigated $(3,12,24$ and $48 \mathrm{~h}$ ); however, in the medulla, $3 \mathrm{~h}$ after LPS injection, there was evidence of IL-6 expression in the thin loops of Henle (fig. 2f). 
Fig. 3. IL-6 stimulates podocyte secretion of Lcn2/Ngal. Fully differentiated podocytes were treated with IL- 6 for $24 \mathrm{~h}$ and Lcn2/Ngal mRNA expression was evaluated (a). Results are the average of studies performed at least three times. ${ }^{*} \mathrm{p}<0.05$ vs. 0 IL-6. b Podocytes were treated for 24 and $48 \mathrm{~h}$ with IL- 6 and Western blotting was performed on concentrated culture supernatants (55 $\mu \mathrm{g} /$ well).

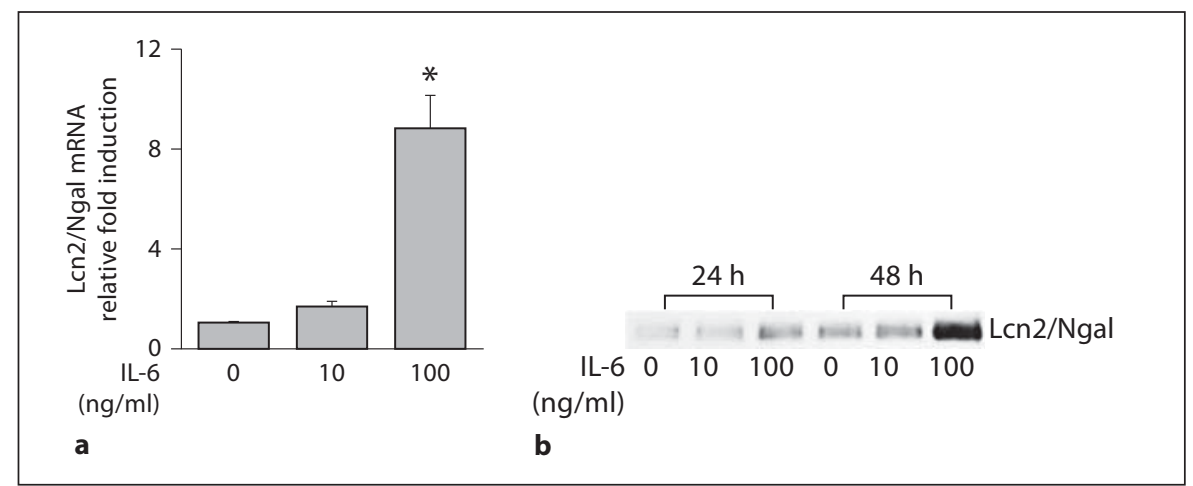

IL-6 Activates Podocyte Expression of Lcn2/Ngal

Intrigued by the findings that podocytes express both IL- 6 and its receptor, we performed microarray analysis to elucidate the downstream effects of IL- 6 signaling in podocytes. Microarray studies revealed that conditionally immortalized podocytes treated with IL-6 upregulate Lcn2/Ngal expression. We confirmed podocyte expression of Lcn $2 / \mathrm{Ngal}$, and quantitative PCR showed an 8-fold induction of Lcn2/Ngal mRNA expression with IL-6 treatment (fig. 3a). Western blotting on concentrated supernatants from IL-6-stimulated podocytes similarly revealed increased Lcn2/Ngal secretion (fig. $3 b$ ).

\section{LPS Stimulates Lcn2/Ngal Expression}

To investigate whether LPS had similar effects on podocyte secretion of Lcn2/Ngal, we treated fully differentiated podocytes with LPS. LPS rapidly and potently stimulated Lcn $2 / \mathrm{Ngal}$ mRNA production in podocytes to levels nearly 20 -fold greater than treatment with exogenous IL-6 (fig. 4a). In contrast to the burst of IL-6 mRNA expression (which was dramatically reduced by $4 \mathrm{~h}$ ) observed after LPS exposure, Lcn2/Ngal mRNA expression increased with LPS treatment in a time-dependent manner. By $24 \mathrm{~h}$, there was a 1,100-fold increase in Lcn2/Ngal mRNA expression with supernatant concentrations of Lcn2/Ngal of 29,370 pg/ml. Western blotting performed on culture supernatants confirmed these findings (fig. 4c).

Primary podocytes were propagated from glomerular preparations of C57BL/6 mice [33]. Podocyte identification was confirmed by immunofluorescence and PCR expression of synaptopodin and WT-1 (fig. 4f). Figure 4d shows that LPS potently augmented Lcn $2 / \mathrm{Ngal}$ mRNA expression in primary podocytes. We also detected Lcn $2 /$ Ngal protein expression in the supernatants of LPS-treated primary podocyte cultures (fig. 4e).

\section{In vivo Podocytes Express Lcn2/Ngal}

In the next set of studies, we evaluated whether in vivo podocytes express Lcn2/Ngal. We developed RNA probes for Lcn2/Ngal and verified dramatic upregulation of Lcn2/Ngal mRNA expression in LPS-treated podocytes (fig. 5). For the in vivo studies, as a positive control to localize podocytes, we performed in situ RNA hybridization for VEGF mRNA expression in the kidneys of PBSand LPS-treated mice (fig. 6b, d) [36]. Figure 6a demonstrates that Lcn2/Ngal mRNA is not highly expressed in the glomeruli of the PBS-treated mice (Lcn2 anti-sense). However, after $24 \mathrm{~h}$ of LPS treatment, there is evidence of glomerular mRNA expression of Lcn2/Ngal mRNA, likely corresponding to podocyte staining (fig. 6e, f). We also observed tubular and glomerular parietal epithelial staining of Lcn $2 / \mathrm{Ngal} 24 \mathrm{~h}$ after LPS treatment. Figure $6 \mathrm{c}$ is a 24-hour LPS-treated kidney section probed with an Lcn2/Ngal sense probe, which serves as a negative control for nonspecific RNA binding. There was also podocyte staining of Lcn2/Ngal in LPS-treated IL-6 KO mice (fig. 6g, h).

\section{LPS-Treated IL-6 KO Mice Develop More \\ Albuminuria}

We also evaluated albuminuria in C57BL/6 mice, IL-6 $\mathrm{KO}$ mice and Lcn2/Ngal KO mice treated with LPS. Figure 7a demonstrates that IL-6 KO mice had significantly higher albuminuria than the PBS controls suggesting that IL- 6 may protect podocyte function. MCP-1 is a potential biomarker for AKI [43], and MCP-1 plays a central role in promoting renal injury in renal inflammatory diseases [for a review, see ref. 44]. We observed a significant increase in MCP-1 mRNA expression in renal cortices of the IL-6 KO mice compared with the PBS controls (fig. 7b). There was a trend for a reduction in podocytespecific mRNAs including nephrin, synaptopodin and 
Fig. 4. LPS augments podocyte expression and secretion of Lcn2/Ngal. Fully differentiated transformed podocytes were treated with LPS $(10 \mathrm{ng} / \mathrm{ml})$ for various time points and Lcn2/Ngal mRNA (a) and supernatant protein expression (b) were evaluated. $\mathrm{C}=$ Control. $\mathbf{c}$ Western blotting was performed on concentrated culture supernatants (23 $\mathrm{\mu g}$ protein/lane) of podocytes treated with graded concentrations of LPS. Primary podocytes derived from C57BL/6 mice were treated with 10 $\mathrm{ng} / \mathrm{ml} \mathrm{LPS}$ and Lcn2/Ngal mRNA (d) and supernatant protein expression (e) was assessed at $24 \mathrm{~h}$. f Primary podocytes were grown on coverslips and stained with classic podocyte markers synaptopodin and WT-1.

Fig. 5. In situ hybridization of Lcn $2 / \mathrm{Ngal}$ mRNA expression in podocytes treated with PBS (a) or LPS (b). Fully differentiated podocytes were treated for $24 \mathrm{~h}$ with LPS $10 \mathrm{ng} / \mathrm{ml}$ and in situ RNA hybridization for Lcn $2 / \mathrm{Ngal}$ was performed. AS = Anti-sense.

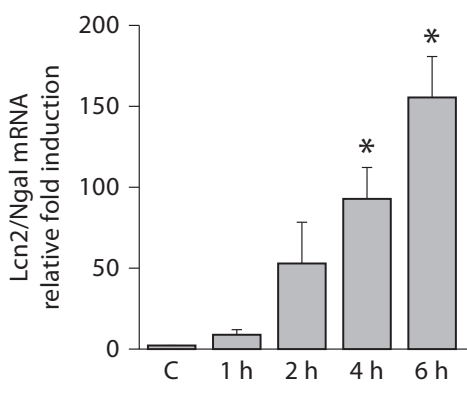
LPS treatment time
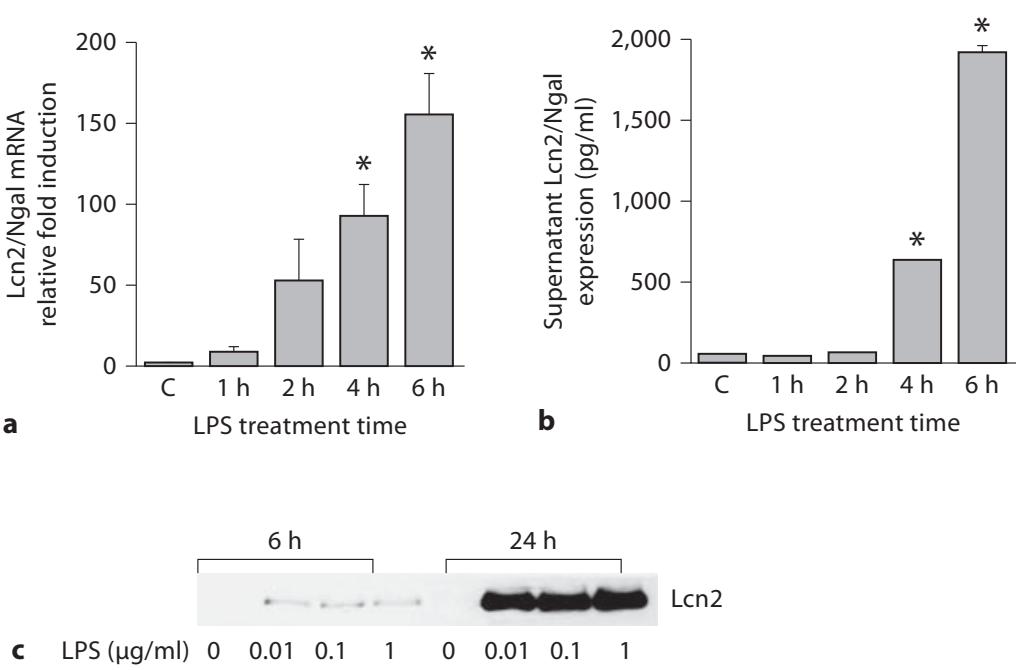

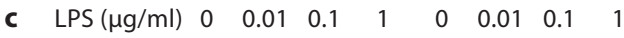

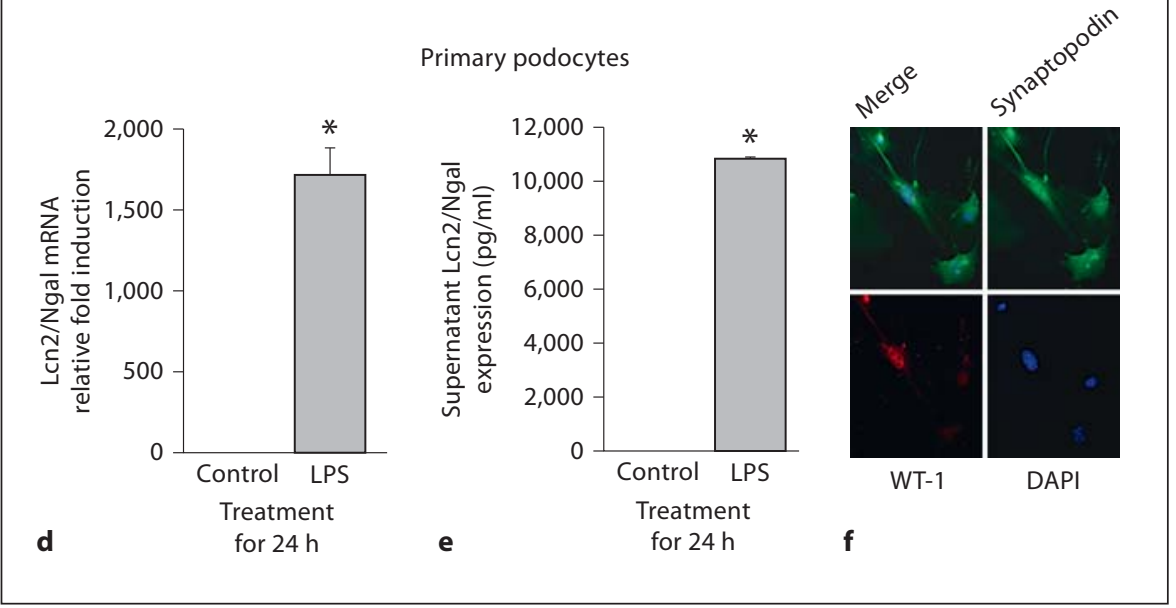

PBS

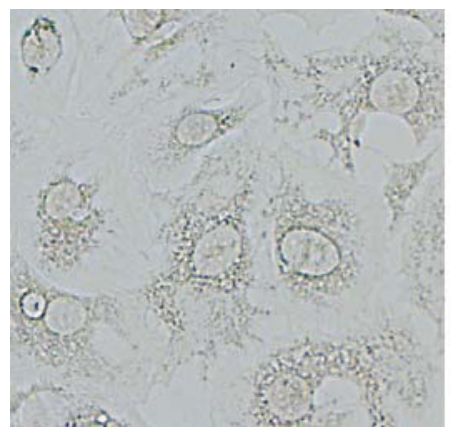

a
Len2 AS
LPS

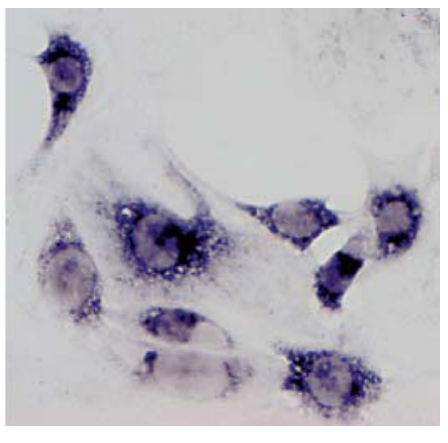

Len2 AS 
Fig. 6. In vivo LPS potently augments glomerular expression of Lcn2/Ngal. C57BL/6 mice were treated with PBS $(\mathbf{a}, \mathbf{b})$ or LPS $(10 \mu \mathrm{g} / \mathrm{g}$ i.p., c-f) and kidneys were harvested 24 h later. Lcn2/Ngal mRNA is not detected in the glomeruli of the PBS-treated mice; however, at $24 \mathrm{~h}$, there is glomerular staining of Lcn2/Ngal mRNA in the LPS-treated mice. VEGF podocyte staining is a positive control $(\mathbf{b}, \mathbf{d}) . \mathbf{c} \operatorname{Lcn} 2$ sense is a negative control for nonspecific RNA binding. IL-6 KO mice were treated with LPS and kidneys were harvested at $48 \mathrm{~h}$ (g, h). AS = Anti-sense.

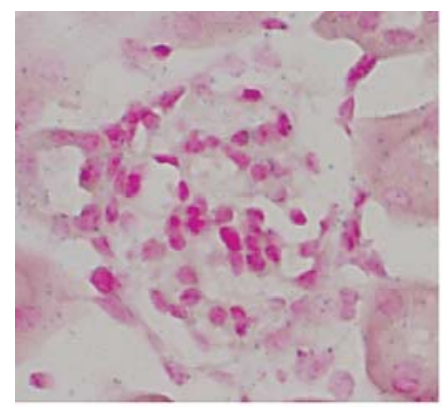

Len2 AS

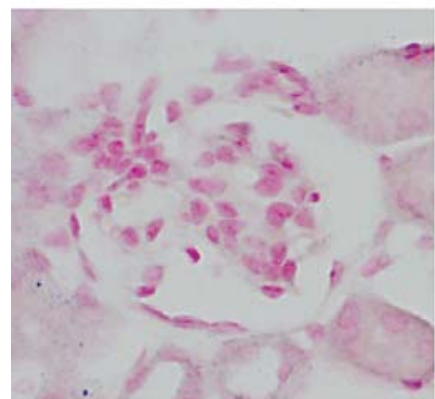

c

Lcn2 Sense

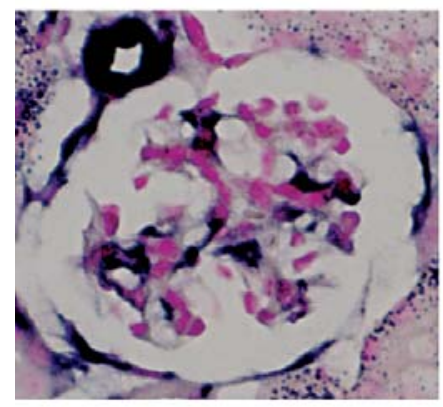

e

Lcn2 AS

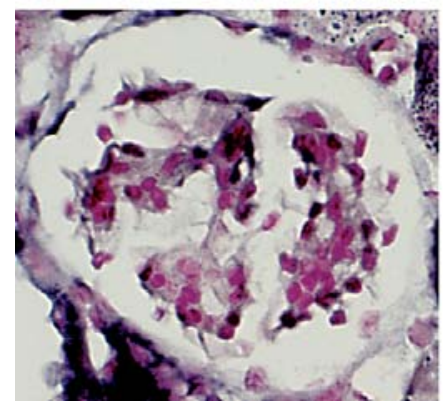

g

Len2 AS

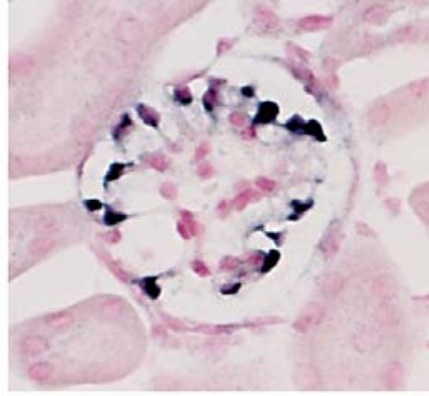

PBS

b

VEGF AS

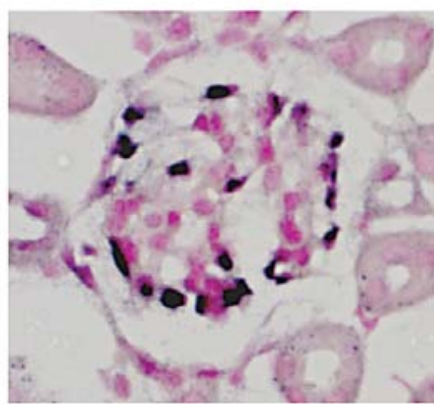

LPS

d VEGF AS

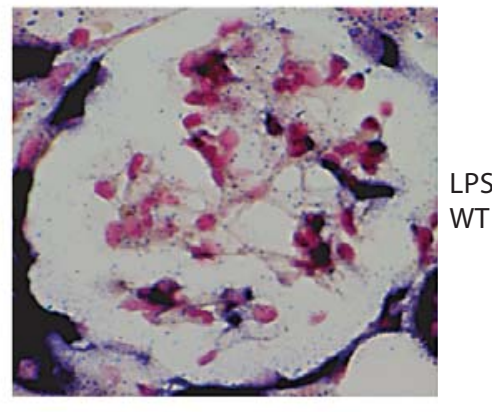

Lcn2 AS

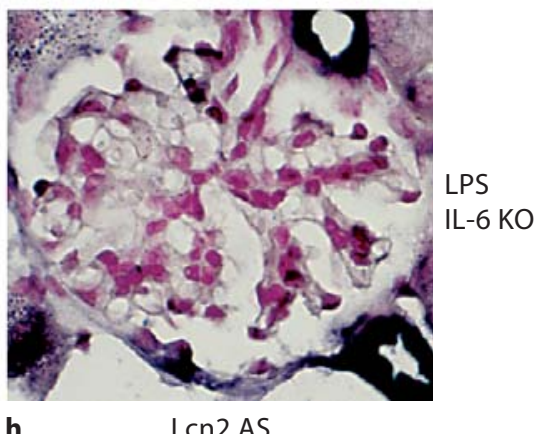

h

Len2 AS 

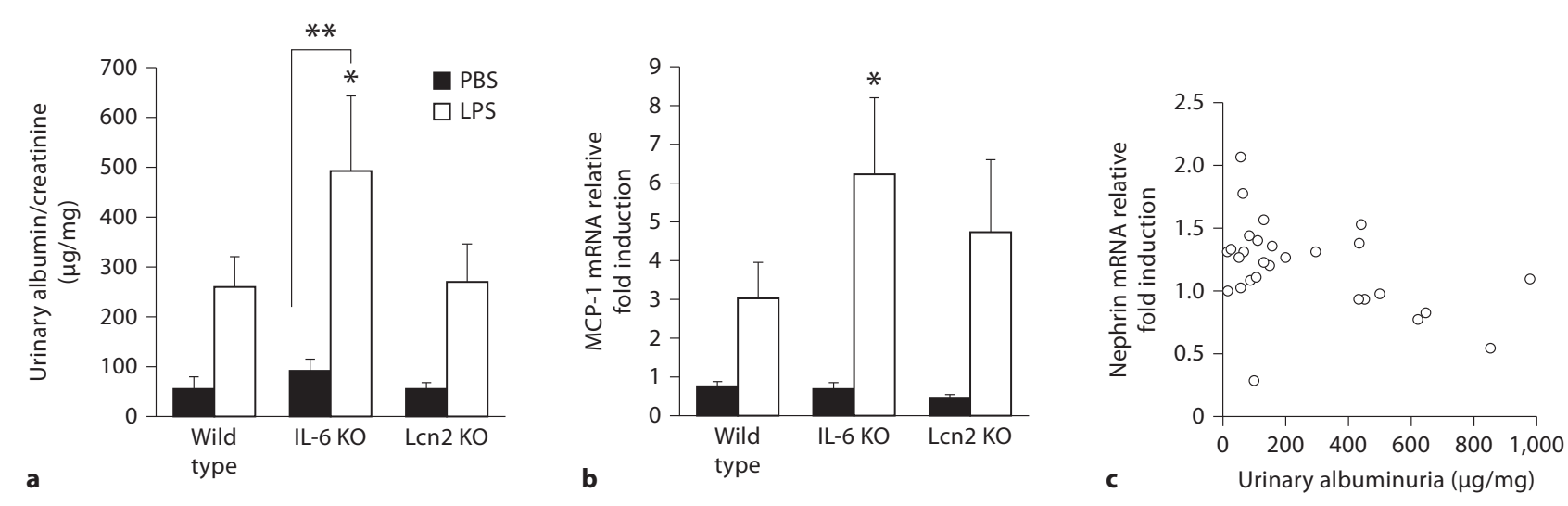

Fig. 7. LPS-treated IL-6 KO mice develop higher albuminuria than wild-type mice. C57BL/6 mice, IL- 6 KO and Lcn2/Ngal KO mice were treated with PBS or LPS and albuminuria was assessed at $48 \mathrm{~h}$ (24-48 h collection). a There is a significant increase in albuminuria in the IL- $6 \mathrm{KO}$ mice: ${ }^{*} \mathrm{p}<0.05$ vs. PBS control and PBS Lcn2/Ngal KO mice, ${ }^{* *} \mathrm{p}<0.05$ vs. IL- 6 KO PBS-treated

mice. b Renal cortical MCP-1 mRNA is higher in the LPS-treated IL-6 KO mice compared with the PBS-treated mice: ${ }^{*} \mathrm{p}<0.05$ vs. PBS control mice. c There is a significant inverse correlation between albuminuria and renal cortical nephrin mRNA expression: $\mathrm{p}<0.05$, Pearson's correlation.

WT-1 expression in renal cortices of LPS-treated IL-6 KO mice compared with the other treatment groups. We also observed a significant inverse correlation between nephrin mRNA expression and albuminuria (fig. 7c), supporting our hypothesis that the albuminuria could be related to podocyte dysfunction.

\section{Discussion}

Inflammation plays a central role in the development of septic AKI. Infiltrating leukocytes, macrophages, lymphocytes and resident tubular and endothelial cells mediate inflammatory changes in the kidney $[2,4,11,45]$. In various conditions, kidney injury is associated with enhanced expression of inflammatory cell markers by podocytes, including CD68, MHC-II, ICAM-1 and B7-1 $[6,46,47]$. Additionally, podocytes secrete cytokines and chemokines and express receptors for chemo-cytokines and complement. Here, we postulate that expression of these immunologic mediators by podocytes could modulate glomerular injury, albuminuria and renal outcome in AKI in sepsis.

In the present study, we show that LPS-treated podocytes rapidly upregulate IL- 6 expression. IL- 6 has been detected in supernatants of fully differentiated human and murine podocyte cultures, and it is suppressible by dexamethasone and activated vitamin D $[16,17,48]$. IL-

6r $\alpha$ is expressed by a limited number of cells [49], and it was first discovered in human urine [38]. Subsequent studies have shown that the kidney expresses low levels of IL-6r $\alpha$, though the specific cell type has not been defined [50]. In this study, we demonstrate for the first time that IL-6r $\alpha$ and gp130 are expressed by podocytes. It is likely that in podocytes IL- 6 signaling is mediated by direct binding of IL- 6 to mIL- 6 r $\alpha$, as we do not see evidence of podocyte secretion of IL-6r $\alpha$ (fig. 1c). In contrast, human mesangial cells [51] and rodent tubular epithelial cells do not express IL-6r $\alpha$ and employ IL- 6 trans-signaling [50].

There are many questions remaining regarding the role that IL-6 plays in podocyte biology. Since podocytes express IL-6r $\alpha$, it is likely that IL- 6 functions in an autocrine or paracrine manner. IL-6 can induce anti-inflammatory effects and inhibit the production of inflammatory cytokines, reduce expression of reactive oxygen species and inhibit cellular apoptosis [for a review, see ref. 25]. Controversy also exists regarding the role of IL-6 in inflammatory diseases, as data suggest that it serves as a marker rather than a mediator of inflammation [26].

Consistent with this study, in ischemia and cisplatininduced AKI, there is a rapid and transient increase in IL-6 expression $[13,52,53]$. However, outcome of AKI in IL-6 KO mice is variable. In ischemic renal failure studies, IL-6 KO mice have shown either improvement or no changes in renal outcome $[13,54,55]$. IL- $6 \mathrm{KO}$ mice are resistant to $\mathrm{HgCl}_{2}$-induced AKI, yet IL- 6 trans-signaling 
prevents AKI perhaps due to upregulation of anti-oxidant pathways [50]. IL- 6 deficiency also accelerates cisplatin-induced AKI [56], and investigators have proposed that IL- 6 may be protective in ischemic renal failure and in a mouse model of rhabdomyolysis-induced AKI [57, 58]. These variable outcomes in IL- $6 \mathrm{KO}$ mice could be due to the doses of injurious factors, experimental time course and definitions of AKI. Alternatively, we propose that these differences are related to the role of IL- 6 as a key immunomodulatory cytokine. IL- 6 mediates the transition from the early innate immune response to the more protective adaptive and resolution phases of inflammation [59]. The effects of IL- 6 are also highly cell type-dependent, and variable outcomes in IL-6 KO mice may be related to cellular expression of other inflammatory mediators, such as a suppressor of cytokine signaling (SOCS3) [60].

We have discovered that exogenous IL- 6 activates podocyte expression of Lcn2/Ngal (fig. 3). Lcn2/ Ngal is an innate immune response mediator that binds bacterial iron-containing siderophores and inhibits the growth of bacteria [61, 62]. Inflammatory stimuli, including LPS, IL-6, IL- $1 \beta$ and IL-17, augment expression of Lcn $2 / \mathrm{Ngal}$, which is upregulated in ischemic kidneys [27, 28, 63]. Plasma and urinary Lcn2/Ngal levels have been proposed as biomarkers for early identification of AKI in a variety of experimental and clinical settings [28, 29]. Most studies have highlighted tubular expression of Lcn $2 / \mathrm{Ngal}$, but its expression also increases in glomerular diseases, including diabetes [64-67], hemolytic uremic syndrome [68], HIV nephropathy [69, 70], systemic lupus erythematosus $[71,72]$ and chronic kidney disease [73]. Using a transgenic Lcn2/Ngal-luciferase reporter mouse, Paragas et al. [27] elegantly showed that ischemia-reperfusion, cisplatin and lipid A induce distal tubular expression of Lcn2/Ngal. They did not report glomerular expression of Lcn $2 / \mathrm{Ngal}$, but this may be related to the time points evaluated and the doses of lipid A. Consistent with their work, our in situ hybridization studies demonstrate that the highest expression of Lcn $2 / \mathrm{Ngal}$ in the kidney is in the renal tubules.

Our studies also show that IL- 6 and LPS induce Lcn2/ Ngal expression. To investigate whether IL-6 is essential for LPS-induced upregulation of Lcn2/Ngal, we used IL6-blocking antibodies in vitro and observed similar increases in Lcn2/Ngal expression. Moreover, LPS-treated IL-6 KO mice had similar increments in kidney and urinary Lcn2/Ngal expression when compared with wildtype controls [unpubl. observations], supporting our in vitro findings. Our findings suggest that LPS enhances additional podocyte-derived molecules, such as TNF- $\alpha$, that activate Lcn2/Ngal expression.

We observed more albuminuria in the LPS-treated IL-6 KO mice, and this was associated with higher MCP1 expression. MCP-1 induces podocyte proliferation and migration [21] and reduces nephrin expression [74]. MCP1 also plays a central role in promoting renal injury [for a review, see ref. 44] and recent work suggests that MCP-1 may serve as a biomarker for AKI [43]. In our study, there were trends for reductions in renal cortical expression of podocyte-specific mRNAs and albuminuria was significantly correlated with decreased cortical nephrin mRNA expression. These findings suggest that the IL-6 KO mice may have developed more podocyte dysfunction compared with the wild-type mice. Notably, LPS-treated Lcn2/Ngal KO mice had similar albuminuria compared with the LPS-treated control mice, suggesting that absence of Lcn2/Ngal did not impair podocyte function in this model system.

In this study, we show for the first time that podocytes express Lcn2/Ngal and that IL- 6 can activate expression of Lcn $2 / \mathrm{Ngal}$. Our studies also demonstrate that the glomerulus secretes inflammatory mediators in septic AKI and suggest that IL-6 may play a role in preservation of optimal podocyte function in sepsis-induced AKI.

\section{Acknowledgments}

A VEGF expression vector (pBluescript-VEGF) and the protocol for in situ hybridization were kind gifts from Dr. Susan Quaggin's laboratory (Samuel Lunenfeld Research Institute, Mount Sinai Hospital, University of Toronto). We also thank Dr. Tak Mak, University of Toronto, Toronto, Ont., Canada for the Lcn2/Ngal $\mathrm{KO}$ mice and Dr. Ravindra L. Metha for his critical reading of the paper and Nazila Sabri for her technical work.

These studies were performed with the support of the Department of Veterans Affairs Career Development Transition Award and Merit Award, UCSD Diabetes and Endocrinology Research Center, NIDDK P30 DK063491, and the University of CaliforniaSan Diego Senate Grant awarded to R.C.

References
1 Bonventre JV, Yang L: Cellular pathophysiology of ischemic acute kidney injury. J Clin Invest 2011;121:4210-4221.

$\checkmark 2$ Zarjou A, Agarwal A: Sepsis and acute kidney injury. J Am Soc Nephrol 2011;22:9991006.

3 Edelstein CL, Schrier R: ARF: pathogenesis, diagnosis and management; in Schrier $\mathrm{R}$ (ed): Renal and Electrolyte Disorders. Philadelphia, Lippincott Williams \& Wilkins, 2003, vol 6, pp 401-455.

Lee/Borsting/Declèves/Singh/Cunard 
-4 Laszik Z, Nadasdy T, Johnson LD, Lerner MR, Brackett D, Silva FG: Renal interleukin-1 expression during endotoxemia and gram-negative septicemia in conscious rats. Circ Shock 1994;43:115-121.

5 Pagtalunan ME, Olson JL, Tilney NL, Meyer TW: Late consequences of acute ischemic injury to a solitary kidney. J Am Soc Nephrol 1999; 10:366-373.

-6 Reiser J, von Gersdorff G, Loos M, Oh J, Asanuma K, Giardino L, Rastaldi MP, Calvaresi N, Watanabe H, Schwarz K, Faul C, Kretzler M, Davidson A, Sugimoto H, Kalluri R, Sharpe AH, Kreidberg JA, Mundel P: Induction of B7-1 in podocytes is associated with nephrotic syndrome. J Clin Invest 2004;113: 1390-1397.

$>7$ Basu S, Bhattacharya M, Chatterjee TK, Chaudhuri S, Todi SK, Majumdar A: Microalbuminuria: a novel biomarker of sepsis. Indian J Crit Care Med 2010;14:22-28.

$>8$ Matsui K, Kamijo-Ikemori A, Hara M, Sugaya T, Kodama T, Fujitani S, Taira Y, Yasuda T, Kimura K: Clinical significance of tubular and podocyte biomarkers in acute kidney injury. Clin Exp Nephrol 2011;15: 220-225.

-9 Mariano F, Cantaluppi V, Stella M, Romanazzi GM, Assenzio B, Cairo M, Biancone L, Triolo G, Ranieri VM, Camussi G: Circulating plasma factors induce tubular and glomerular alterations in septic burns patients. Crit Care 2008;12:R42.

-10 Kato T, Mizuno-Horikawa Y, Mizuno S: Decreases in podocin, CD2-associated protein (CD2AP) and tensin 2 may be involved in albuminuria during septic acute renal failure. J Vet Med Sci 2011;73:1579-1584.

$\checkmark 11$ Lee DW, Faubel S, Edelstein CL: Cytokines in acute kidney injury (AKI). Clin Nephrol 2011;76:165-173.

-12 Cunningham PN, Wang Y, Guo R, He G, Quigg RJ: Role of Toll-like receptor 4 in endotoxin-induced acute renal failure. J Immunol 2004;172:2629-2635.

-13 Kielar ML, John R, Bennett M, Richardson JA, Shelton JM, Chen L, Jeyarajah DR, Zhou XJ, Zhou H, Chiquett B, Nagami GT, Lu CY: Maladaptive role of IL- 6 in ischemic acute renal failure. J Am Soc Nephrol 2005;16: 3315-3325.

- 14 Fukatsu A, Matsuo S, Yuzawa Y, Miyai H, Futenma A, Kato K: Expression of interleukin 6 and major histocompatibility complex molecules in tubular epithelial cells of diseased human kidneys. Lab Invest 1993;69: 58-67.

-15 Niemir ZI, Stein H, Dworacki G, Mundel P, Koehl N, Koch B, Autschbach F, Andrassy K, Ritz E, Waldherr R, Otto HF: Podocytes are the major source of IL-1 alpha and IL-1 beta in human glomerulonephritides. Kidney Int 1997;52:393-403.

-16 Xing CY, Saleem MA, Coward RJ, Ni L, Witherden IR, Mathieson PW: Direct effects of dexamethasone on human podocytes. Kidney Int 2006;70:1038-1045.
17 Matsumoto T, Hess S, Kajiyama H, Sakairi T, Saleem MA, Mathieson PW, Nojima Y, Kopp JB: Proteomic analysis identifies insulin-like growth factor-binding proteinrelated protein-1 as a podocyte product. Am J Physiol Renal Physiol 2010;299:F776F784.

-18 Niemir ZI, Stein H, Ciechanowicz A, Olejniczak P, Dworacki G, Ritz E, Waldherr R, Czekalski S: The in situ expression of interleukin-8 in the normal human kidney and in different morphological forms of glomerulonephritis. Am J Kidney Dis 2004;43:983998.

19 Chow FY, Nikolic-Paterson DJ, Ozols E, Atkins RC, Rollin BJ, Tesch GH: Monocyte chemoattractant protein-1 promotes the development of diabetic renal injury in streptozotocin-treated mice. Kidney Int 2006;69 73-80.

-20 Gu L, Hagiwara S, Fan Q, Tanimoto M, Kobata M, Yamashita M, Nishitani T, Gohda T, Ni Z, Qian J, Horikoshi S, Tomino Y: Role of receptor for advanced glycation end-products and signalling events in advanced glycation end-product-induced monocyte chemoattractant protein-1 expression in differentiated mouse podocytes. Nephrol Dial Transplant 2006;21:299-313.

21 Burt D, Salvidio G, Tarabra E, Barutta F, Pinach S, Dentelli P, Camussi G, Perin PC, Gruden G: The monocyte chemoattractant protein-1/cognate CC chemokine receptor 2 system affects cell motility in cultured human podocytes. Am J Pathol 2007;171:17891799.

22 Morse E, Schroth J, You YH, Pizzo DP, Okada S, Ramachandrarao S, Vallon V, Sharma $\mathrm{K}$, Cunard R: TRB3 is stimulated in diabetic kidneys, regulated by the ER stress marker CHOP, and is a suppressor of podocyte MCP 1. Am J Physiol Renal Physiol 2010;299:F965F972.

23 Simmons EM, Himmelfarb J, Sezer MT, Chertow GM, Mehta RL, Paganini EP, Soroko S, Freedman S, Becker K, Spratt D, Shyr Y, Ikizler TA: Plasma cytokine levels predict mortality in patients with acute renal failure. Kidney Int 2004;65:1357-1365.

24 Chawla LS, Seneff MG, Nelson DR, Williams M, Levy H, Kimmel PL, Macias WL: Elevated plasma concentrations of IL- 6 and elevated APACHE II score predict acute kidney injury in patients with severe sepsis. Clin J Am Soc Nephrol 2007;2:22-30.

25 Mitazaki S, Kato N, Suto M, Hiraiwa K, Abe S: Interleukin-6 deficiency accelerates cisplatin-induced acute renal failure but not systemic injury. Toxicology 2009;265:115-121.

26 Song L, Schindler C: IL- 6 and the acute phase response in murine atherosclerosis. Atherosclerosis 2004; 177:43-51.

27 Paragas N, Qiu A, Zhang Q, Samstein B, Deng SX, Schmidt-Ott KM, Viltard M, Yu W, Forster CS, Gong G, Liu Y, Kulkarni R, Mori K, Kalandadze A, Ratner AJ, Devarajan P, Landry DW, D’Agati V, Lin CS, Barasch J:
The Ngal reporter mouse detects the response of the kidney to injury in real time. Nat Med 2011;17:216-222.

28 Mishra J, Ma Q, Prada A, Mitsnefes M, Zahedi K, Yang J, Barasch J, Devarajan P: Identification of neutrophil gelatinase-associated lipocalin as a novel early urinary biomarker for ischemic renal injury. J Am Soc Nephrol 2003;14:2534-2543.

29 Siew ED, Ware LB, Gebretsadik T, Shintani A, Moons KG, Wickersham N, Bossert F, Ikizler TA: Urine neutrophil gelatinase-associated lipocalin moderately predicts acute kidney injury in critically ill adults. J Am Soc Nephrol 2009;20:1823-1832.

30 Bagshaw SM, Bennett M, Haase M, HaaseFielitz A, Egi M, Morimatsu H, D’Amico G, Goldsmith D, Devarajan P, Bellomo R: Plasma and urine neutrophil gelatinase-associated lipocalin in septic versus non-septic acute kidney injury in critical illness. Intensive Care Med 2010;36:452-461.

31 Berger T, Togawa A, Duncan GS, Elia AJ, You-Ten A, Wakeham A, Fong HE, Cheung CC, Mak TW: Lipocalin 2-deficient mice exhibit increased sensitivity to Escherichia coli infection but not to ischemia-reperfusion injury. Proc Natl Acad Sci USA 2006;103:18341839.

32 Shankland SJ, Pippin JW, Reiser J, Mundel P: Podocytes in culture: past, present, and future. Kidney Int 2007;72:26-36.

33 Takemoto M, Asker N, Gerhardt H, Lundkvist A, Johansson BR, Saito Y, Betsholtz C: A new method for large scale isolation of kidney glomeruli from mice. Am J Pathol 2002; 161:799-805.

34 Pfaffl MW: A new mathematical model for relative quantification in real-time RT-PCR. Nucleic Acids Res 2001;29:e45.

35 Morse E, Selim E, Cunard R: PPAR $\alpha$ ligands cause lymphocyte depletion and cell cycle block and this is associated with augmented TRB3 and reduced cyclin B1 expression. Mol Immunol 2009;46:3454-3461.

-36 Eremina V, Sood M, Haigh J, Nagy A, Lajoie G, Ferrara N, Gerber HP, Kikkawa Y, Miner JH, Quaggin SE: Glomerular-specific alterations of VEGF-A expression lead to distinct congenital and acquired renal diseases. J Clin Invest 2003;111:707-716.

37 Opal SM: Endotoxins and other sepsis triggers. Contrib Nephrol 2010;167:14-24.

-38 Novick D, Engelmann H, Wallach D, Leitner O, Revel M, Rubinstein M: Purification of soluble cytokine receptors from normal human urine by ligand-affinity and immunoaffinity chromatography. J Chromatogr 1990;510:331-337.

39 Hibi M, Murakami M, Saito M, Hirano T, Taga T, Kishimoto T: Molecular cloning and expression of an IL-6 signal transducer, gp130. Cell 1990;63:1149-1157.

40 Kamimura D, Ishihara K, Hirano T: IL-6 signal transduction and its physiological roles: the signal orchestration model. Rev Physiol Biochem Pharmacol 2003;149:1-38. 
-41 Yamasaki K, Taga T, Hirata Y, Yawata H, Kawanishi Y, Seed B, Taniguchi T, Hirano T, Kishimoto T: Cloning and expression of the human interleukin-6 (BSF-2/IFN beta 2) receptor. Science 1988;241:825-828.

-42 Rose-John S, Scheller J, Elson G, Jones SA: Interleukin- 6 biology is coordinated by membrane-bound and soluble receptors: role in inflammation and cancer. J Leukoc Biol 2006;80:227-236.

-43 Munshi R, Johnson A, Siew ED, Ikizler TA, Ware LB, Wurfel MM, Himmelfarb J, Zager RA: MCP-1 gene activation marks acute kidney injury. J Am Soc Nephrol 2011;22:165175

44 Kelley VR, Rovin BH: Chemokines: therapeutic targets for autoimmune and inflammatory renal disease. Springer Semin Immunopathol 2003;24:411-421.

45 Jang HR, Ko GJ, Wasowska BA, Rabb H: The interaction between ischemia-reperfusion and immune responses in the kidney. J Mol Med 2009;87:859-864.

46 Bariety J, Nochy D, Mandet C, Jacquot C, Glotz D, Meyrier A: Podocytes undergo phenotypic changes and express macrophagicassociated markers in idiopathic collapsing glomerulopathy. Kidney Int 1998;53:918925.

$\checkmark 47$ Coers W, Brouwer E, Vos JT, Chand A, Huitema S, Heeringa P, Kallenberg CG, Weening JJ: Podocyte expression of $\mathrm{MHC}$ class I and II and intercellular adhesion molecule-1 (ICAM-1) in experimental pauci-immune crescentic glomerulonephritis. Clin Exp Immunol 1994;98:279-286.

48 Sanchez-Nino MD, Bozic M, CordobaLanus E, Valcheva P, Gracia O, Ibarz M, Fernandez E, Navarro-Gonzalez JF, Ortiz A, Valdivielso JM: Beyond proteinuria: VDR activation reduces renal inflammation in experimental diabetic nephropathy. Am J Physiol Renal Physiol 2012;302:F647-F657.

-49 Schoester M, Heinrich PC, Graeve L: Regulation of interleukin- 6 receptor expression by interleukin-6 in human monocytes - a reexamination. FEBS Lett 1994;345:131-134.

-50 Nechemia-Arbely Y, Barkan D, Pizov G, Shriki A, Rose-John S, Galun E, Axelrod JH: IL-6/IL-6R axis plays a critical role in acute kidney injury. J Am Soc Nephrol 2008;19: 1106-1115.

-51 Coletta I, Soldo L, Polentarutti N, Mancini F, Guglielmotti A, Pinza M, Mantovani A, Milanese C: Selective induction of MCP-1 in human mesangial cells by the IL-6/SIL-6R complex. Exp Nephrol 2000;8:37-43.

52 Vannay A, Fekete A, Langer R, Toth T, Sziksz E, Vasarhelyi B, Szabo AJ, Losonczy G, Adori C, Gal A, TulassayT, Szabo A: Dehydroepiandrosterone pretreatment alters the ischaemia/reperfusion-induced VEGF, IL-1 and IL-6 gene expression in acute renal failure. Kidney Blood Press Res 2009;32:175-184.

53 Faubel S, Lewis EC, Reznikov L, Ljubanovic D, Hoke TS, Somerset H, Oh DJ, Lu L, Klein CL, Dinarello CA, Edelstein CL: Cisplatin- induced acute renal failure is associated with an increase in the cytokines interleukin (IL)1beta, IL-18, IL-6, and neutrophil infiltration in the kidney. J Pharmacol Exp Ther 2007;322:8-15.

54 Patel NS, Chatterjee PK, Di Paola R, Mazzon E, Britti D, De Sarro A, Cuzzocrea S, Thiemermann C: Endogenous interleukin-6 enhances the renal injury, dysfunction, and inflammation caused by ischemia/reperfusion. J Pharmacol Exp Ther 2005;312: 1170-1178.

55 Klein CL, Hoke TS, Fang WF, Altmann CJ, Douglas IS, Faubel S: Interleukin- 6 mediates lung injury following ischemic acute kidney injury or bilateral nephrectomy. Kidney Int 2008;74:901-909.

56 Mitazaki S, Honma S, Suto M, Kato N, Hiraiwa $K$, Yoshida $M$, Abe S: Interleukin-6 plays a protective role in development of cisplatin-induced acute renal failure through upregulation of anti-oxidative stress factors. Life Sci 2011;88:1142-1148.

57 Yokota N, O’Donnell M, Daniels F, BurneTaney M, Keane W, Kasiske B, Rabb H: Protective effect of HMG-CoA reductase inhibitor on experimental renal ischemia-reperfusion injury. Am J Nephrol 2003;23:13-17.

58 Kato N, Abe S, Suto M, Hiraiwa K: Comparison of renal dysfunction in wild-type, IL-6 $\mathrm{KO}$ and iNOS KO mice hind limb tourniquet-reperfusion model. Leg Med (Tokyo) 2009;11(suppl 1):S248-S251.

59 Hurst SM, Wilkinson TS, McLoughlin RM, Jones S, Horiuchi S, Yamamoto N, Rose-John S, Fuller GM, Topley N, Jones SA: IL-6 and its soluble receptor orchestrate a temporal switch in the pattern of leukocyte recruitment seen during acute inflammation. Immunity 2001;14:705-714.

60 Yasukawa H, Ohishi M, Mori H, Murakami M, Chinen T, Aki D, Hanada T, Takeda K, Akira S, Hoshijima M, Hirano T, Chien KR, Yoshimura A: IL-6 induces an anti-inflammatory response in the absence of SOCS3 in macrophages. Nat Immunol 2003;4:551-556.

61 Schmidt-Ott KM, Mori K, Li JY, Kalandadze A, Cohen DJ, Devarajan P, Barasch J: Dual action of neutrophil gelatinase-associated lipocalin. J Am Soc Nephrol 2007;18:407-413.

62 Goetz DH, Holmes MA, Borregaard N, Bluhm ME, Raymond KN, Strong RK: The neutrophil lipocalin NGAL is a bacteriostatic agent that interferes with siderophore-mediated iron acquisition. Mol Cell 2002;10: 1033-1043.

63 Luchtefeld M, Preuss C, Ruhle F, Bogalle EP, Sietmann A, Figura S, Muller W, Grote K, Schieffer B, Stoll M: Gp130-dependent release of acute phase proteins is linked to the activation of innate immune signaling pathways. PLoS One 2011;6:e19427.

64 Kuwabara T, Mori K, Mukoyama M, Kasahara M, Yokoi H, Saito Y, Yoshioka T, Ogawa Y, Imamaki H, Kusakabe T, Ebihara K, Omata M, Satoh N, Sugawara A, Barasch J, Nakao $\mathrm{K}$ : Urinary neutrophil gelatinase-associated lipocalin levels reflect damage to glomeruli, proximal tubules, and distal nephrons. Kidney Int 2009;75:285-294.

65 Yang YH, He XJ, Chen SR, Wang L, Li EM, $\mathrm{Xu}$ LY: Changes of serum and urine neutrophil gelatinase-associated lipocalin in type-2 diabetic patients with nephropathy: one year observational follow-up study. Endocrine 2009;36:45-51.

-66 Bolignano D, Lacquaniti A, Coppolino G, Donato V, Fazio MR, Nicocia G, Buemi M: Neutrophil gelatinase-associated lipocalin as an early biomarker of nephropathy in diabetic patients. Kidney Blood Press Res 2009; 32:91-98.

67 Nielsen SE, Andersen S, Zdunek D, Hess G, Parving HH, Rossing P: Tubular markers do not predict the decline in glomerular filtration rate in type 1 diabetic patients with overt nephropathy. Kidney Int 2011;79:11131118.

68 Trachtman H, Christen E, Cnaan A, Patrick J, Mai V, Mishra J, Jain A, Bullington N, Devarajan P: Urinary neutrophil gelatinase-associated lipocalcin in D+HUS: a novel marker of renal injury. Pediatr Nephrol 2006;21: 989-994.

69 Damas JK, Baekken M, Ueland T, Manner IW, Os I, Yndestad A, Flo TH, Oktedalen O, Aukrust P: Serum levels of neutrophil gelatinase-associated lipocalin are associated with microalbuminuria in $\mathrm{HIV}$-infected patients. J Acquir Immune Defic Syndr 2012;59:e24e25.

70 Sola-Del Valle DA, Mohan S, Cheng JT, Paragas NA, Sise ME, D’Agati VD, Barasch J: Urinary NGAL is a useful clinical biomarker of HIV-associated nephropathy. Nephrol Dial Transplant 2011;26:2387-2390.

71 Rubinstein T, Pitashny M, Levine B, Schwartz N, Schwartzman J, Weinstein E, Pego-Reigosa JM, Lu TY, Isenberg D, Rahman A, Putterman C: Urinary neutrophil gelatinase-associated lipocalin as a novel biomarker for disease activity in lupus nephritis. Rheumatology (Oxford) 2010;49: 960-971.

72 Rubinstein T, Pitashny M, Putterman C: The novel role of neutrophil gelatinase-B associated lipocalin (NGAL)/lipocalin-2 as a biomarker for lupus nephritis. Autoimmun Rev 2008;7:229-234.

73 Viau A, El Karoui K, Laouari D, Burtin M, Nguyen C, Mori K, Pillebout E, Berger T, Mak TW, Knebelmann B, Friedlander G, Barasch J, Terzi F: Lipocalin 2 is essential for chronic kidney disease progression in mice and humans. J Clin Invest 2010;120:40654076

74 Tarabra E, Giunti S, Barutta F, Salvidio G, Burt D, Deferrari G, Gambino R, Vergola D, Pinach S, Perin PC, Camussi G, Gruden G: Effect of the monocyte chemoattractant protein-1/CC chemokine receptor 2 system on nephrin expression in streptozotocin-treated mice and human cultured podocytes. Diabetes 2009;58:2109-2118. 